\title{
Awareness of Breast Developmental Anomalies: A Study in Jamasi, Ghana
}

\author{
P. Agbenorku • M. Agbenorku • A. Iddi • \\ E. Amevor $\cdot$ M. Kofitse $\cdot$ E. Klutsey
}

Received: 27 October 2010/Accepted: 11 February 2011/Published online: 1 April 2011

(C) The Author(s) 2011. This article is published with open access at Springerlink.com

\begin{abstract}
Background Few global studies investigating breast developmental anomalies (BDA) among young females have been conducted. This study aimed to evaluate the degree of BDA awareness among young females in central Ghana.

Methods In February 2008, clinical breast examination was performed for both breasts of female volunteers at five selected junior high schools (JHS) in Jamasi, Ghana. Anonymous pretested questionnaires were administered to those found to have BDA.

Results Of the 600 female students surveyed, 78 (13\%) were found to have BDA. All 78 females completed the questionnaire. The respondents ranged in age from 12 to 21 years (mean 15.3 years). Most of the respondents (83\%) had some knowledge of BDA. Although $63 \%$ had been aware of their own BDA for $1-3$ years before the survey; $78 \%$ did not know the cause of their BDA. According to their self-reports, BDA had no influence on the schooling of $78.2 \%$ or the family of $70.5 \%$ of the respondents.
\end{abstract}

P. Agbenorku $(\square)$

Reconstructive Plastic Surgery and Burns Unit,

School of Medical Sciences, Komfo Anokye Teaching Hospital,

Kwame Nkrumah University of Science and Technology,

University P. O. Box 448, KNUST-Kumasi, Ghana

e-mail: pimagben@yahoo.com

M. Agbenorku · A. Iddi

Health Education Unit, Global Evangelical Mission Hospital,

Apromase-Ashanti, Ghana

E. Amevor · M. Kofitse

South Tongu District Hospital, Sogakope, Volta Region, Ghana

E. Klutsey

Nurses' Training College, Ho, Volta Region, Ghana
Conclusion Awareness of BDA among the JHS females in Jamasi is high. Appropriate education and treatment should be encouraged for continual management of a high awareness level for BDA.

Keywords Breast developmental anomalies (BDA) . Clinical breast examination (CBE) - Awareness

The female breast compared with other organs of a woman's body is multifunctional in the sense that it not only indicates health but also embodies femininity and is an important physical asset. A woman's breasts are subject to a series of changes throughout her lifetime. These changes are attributable to volatile hormonal fluctuations occurring from puberty to menopause. Other attributes include genetic factors, environmental factors, and exposure to infectious agents [4]. If traumatic, neoplastic, or endocrine conditions do not intervene during infancy, the breasts grow to their potential at puberty [14]. Some of the anomalies that may develop are not recognized until full growth has been attained, and some are not detected until the onset of pregnancy [15].

Kosters and Gotzsche [8] stated that many women currently practice periodic self-examination of their breasts. Clinical breast examination (CBE) refers to examination of the breasts by a trained health professional. The examination is focused on detecting changes in the breasts such as skin changes, nipple discharge, lumpiness, or changes in size or shape.

Because breast developmental anomalies (BDA) usually are neither painful nor life threatening, health education on the subject has been minimal compared with education for traditional breast diseases such as breast cancer. It is therefore very difficult for the adolescent girl even to know 
that her breast development is abnormal for some forms of BDA [1].

In Australia, more than $50 \%$ of the breast cancer diagnoses result from investigation of a breast change noted by a woman or her physician. The importance of a woman's awareness concerning the normal appearance and feel of her breasts is therefore clear [5].

Hypertrophy of the breast, gigantomastia, or macromastia is a rare connective tissue disorder. It has been qualified as enlargement of the breast exceeding $600 \mathrm{~g}$ (21 oz), causing discomfort and stretching of the overlying skin and leading to ulceration [16]. When young women experience gigantomastia during puberty, the medical condition is known as "juvenile macromastia" or "juvenile gigantomastia" and sometimes as "virginal breast hypertrophy." Together with the excessive breast size, other symptoms include darkening itchy lesions and pains in the breasts.

A diagnosis is made when an adolescent's breasts grow rapidly and achieve great weight, usually soon after her first menstrual period [3]. Other forms of BDA include polythelia (extra nipple), polymastia (extra breast), aplasia (absence of breast), hypomastia (underdeveloped breast), and tubular breast (breast with a tube-like shape) [12].

McMenamin et al. [11], reporting on a study in the general Irish population, identified sources of information on BDA and breast cancer as well as factors associated with awareness and knowledge of the condition. Participants ( $n=2355,53 \%$ females) completed a questionnaire, and most $(81 \%)$ had seen or heard something about BDA and breast cancer in the recent past.

A Nigerian consultant oncologist identified lack of awareness, lack of modern diagnostic facilities, inadequate treatment centers, inadequate specialists, and poverty as problems leading to increased breast anomalies and diseases, adding that breast screening should be a part of a routine medical checkup. Onwere et al. [13] reported that only $34 \%$ of patients attending for CBE knew the purpose of breast examination, whereas only 1 and $2 \%$ had received CBE by physicians and nurses, respectively, during the current antenatal period. The Ghana News Agency reported on a Breast Cancer Awareness Seminar held in the Ho Municipality in the Volta Region of Ghana for female teachers, stating that women from all sorts of social boundaries shun expert advice on BDA and breast diseases but instead attach various beliefs to such conditions [2].

Studies on awareness of BDA are rare compared with studies on awareness of breast cancer. The current study was aimed at establishing a baseline for awareness of BDA in the central part of Ghana. Subsequent studies in different parts of the country then could be compared with the current findings, thereby highlighting the knowledge of early detection and treatment of BDA among young females.

\section{Materials and Methods}

\section{Study Setting}

Jamasi is located $5 \mathrm{~km}$ south of Agona, the district capital town of the Sekyere South District of the Ashanti Region. It lies between latitudes $6^{\circ} 50^{\prime} \mathrm{N}$ and $7^{\circ} 10^{\prime} \mathrm{N}$ and between longitudes $1^{\circ} 40^{\prime} \mathrm{W}$ and $1^{\circ} 25^{\prime} \mathrm{W}$. The total population of the community is approximately 35,000 , and it is 45 min drive south to the regional capital, Kumasi. The people of the town are mostly segmented into three religious groups, namely, Christian, Muslim, and traditional believers. The main occupations of the people are farming, trading, and carving (Ghanadistrict.com 2010).

\section{Methods and Data Analysis}

After appropriate ethical clearance was obtained from the Sekyere South District Health Directorate through the Sekyere South District Education Directorate for the study, a CBE was conducted in February 2008 for 600 females ranging in age from 12 to 21 years. The respondents were female students at five selected junior high schools (JHS) in Jamasi. The ten member research team was made up of physicians, nurses, biostatisticians, a health educator, and a social worker.

The CBE was reported to be normal when no abnormal findings were noted after observation and palpation of the breasts, the axilla, and the supra- and infraclavicular fossae. A volunteer was said to have macromastia (juvenile macromastia) when enlargement of the breast exceeded $600 \mathrm{~g}$; polythelia when accessory nipples were present; polymastia when there was an extra breast, aplasia, or total absence of a breast or breasts; hypomastia when the breast was underdeveloped (very small, peanut size); and tubular breast when the shape of the breasts was tube-like.

Anonymous questionnaires, initially administrated to ten JHS female students with BDA at a different school in Jamasi and later adjusted to include other relevant study information, were administrated to respondents with a diagnosis of BDA. The students were taken through the questionnaires with the use of simple English or their indigenous language to obtain all the required information for the study. Epi Info 2000 (CDC, Atlanta, GA, USA) was used in the presentation of the descriptive statistics. 


\section{Results}

Recorded Demographic Data and Medical Information on BDA

Figure 1 shows the age distribution of the female students with BDA, and Fig. 2 illustrates the different types of anomalies found. More than half of the respondents (71.8\%) were 14-17 years old, whereas the youngest (ages 12-13 years) and oldest (ages 20-21 years) had minimal representation (Fig. 1). Juvenile macromastia was the BDA diagnosis recorded the most often $(43.6 \%)$, followed by hypomastia (21.8\%) and aplasia (6.4\%) (Fig. 2).

Respondents' Awareness Level and Knowledge of BDA

Table 1 indicates that $63 \%$ of the female students had been aware of their BDA for 1-3 years, whereas $19 \%$ could not remember exactly when they had noticed the BDA before the study. As shown in Table 2, a high number of the

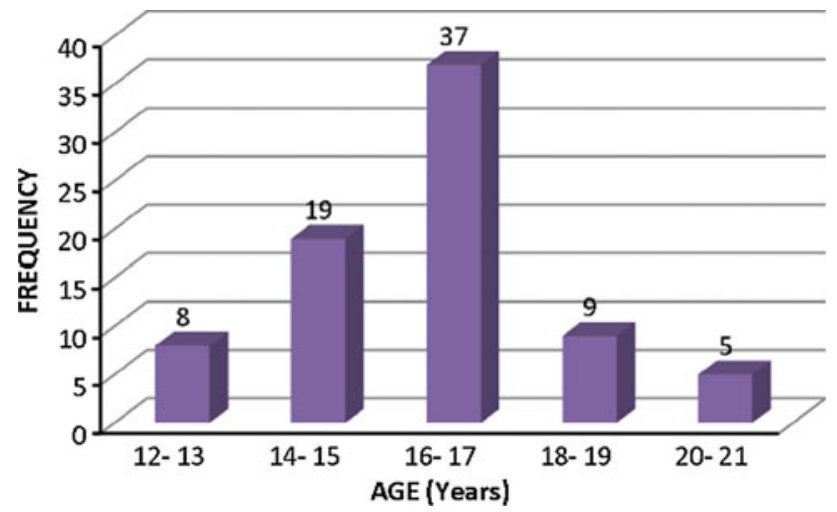

Fig. 1 Age distribution of respondents with breast developmental anomalies (BDA)

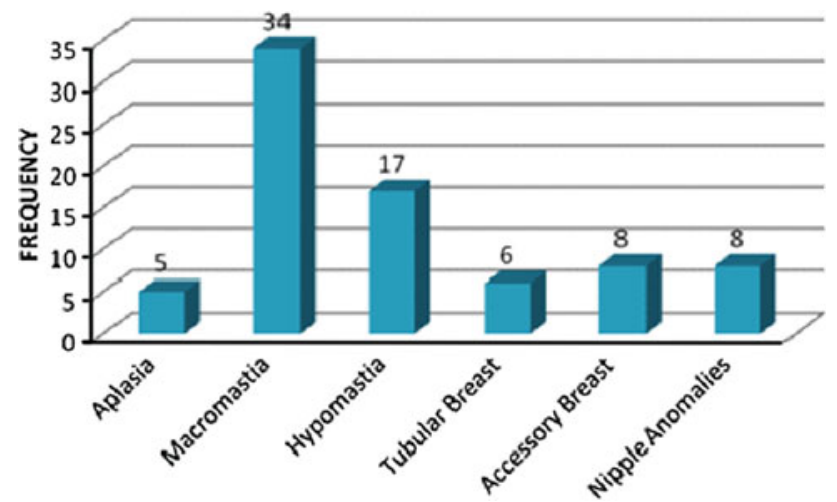

Fig. 2 Forms of breast developmental anomalies (BDA) recorded among the respondents
Table 1 Period when respondents noticed the breast developmental anomalies (BDA)

\begin{tabular}{lcr}
\hline Years & Frequency $(n)$ & $\%$ \\
\hline $0^{\mathrm{a}}$ & 15 & 19 \\
1 & 30 & 38 \\
2 & 7 & 9 \\
3 & 13 & 16 \\
4 & 6 & 7 \\
5 & 2 & 3 \\
6 & 2 & 3 \\
9 & 3 & 5 \\
Total & 78 & 100 \\
\hline
\end{tabular}

${ }^{a} 0$ represents those who could not remember the exact time

respondents $(83 \%)$ had heard about BDA, but the majority (99\%) had never sought medical intervention. In terms of treatment, most of the respondents $(68 \%)$ were ready to accept medications (drugs) as the only treatment for their BDA. Surgery and other forms of treatment such as counseling and regular follow-up assessments were minimal (Fig. 3). The majority of the respondents $(n=61$, $78 \%$ ) had no knowledge concerning the causes of BDA (Table 3).

Problems Respondents Faced Among Family Members and in School

The majority of the respondents affirmed that BDA had no influence on their experience with family $(70.5 \%)$ or school (78.2\%). However, $20.5 \%$ reported teasing in the family, and $6.1 \%$ reported shyness at school (Table 4 ).

\section{Discussion}

Anomalies of normal breast development can result in poor self-esteem or make the adolescent feel self-conscious. In terms of ethnicity, Simmons [17] reported polythelia (extra nipple) and breast asymmetry as the most common forms of BDA among the adolescent girls in his study at Rochester, USA. Haagensen [7] reported that an extra breast (polymastia) or polythelia occurs in approximately $1 \%$ of the Caucasian population and that it may be an inheritable condition. A Japanese study showed that 5\% of young females had accessory nipples, whereas a report from a review of 10,000 school children in England demonstrated an incidence of only $0.4 \%$ [6,9]. Agbenorku et al. [1] reported macromastia (grossly enlarged breast) as the most common type of BDA among Ghanaians (black Africans) at a clinical setting in Kumasi in the central part of Ghana. 
Table 2 Information of respondents related to breast developmental anomalies (BDA)

\begin{tabular}{lccc}
\hline Question & $\begin{array}{l}\text { Yes } \\
n(\%)\end{array}$ & $\begin{array}{l}\text { No } \\
n(\%)\end{array}$ & $\begin{array}{l}\text { No response } \\
n(\%)\end{array}$ \\
\hline Have you heard or know about BDA? & $65(83)$ & $13(17)$ & 0 \\
Have you sought medical attention? & $1(1)$ & $77(99)$ & 0 \\
If treatment is made available to you, will you accept it? & $63(81)$ & $15(19)$ & 0 \\
Do you have a child? & $3(4)$ & $75(96)$ & 0 \\
Were you able to breastfeed the child? & $2(3)$ & $1(1)$ & $75(96)$ \\
Is BDA among females in your extended family? & $24(31)$ & $23(29)$ & $31(40)$ \\
\hline
\end{tabular}

The current study, which included black Africans as subjects, showed that macromastia still is the most prevalent BDA in central Ghana (Fig. 2), with only a few nipple anomaly cases reported among the 12-13 year old students. Macromastia was found in $43.6 \%$ of those with

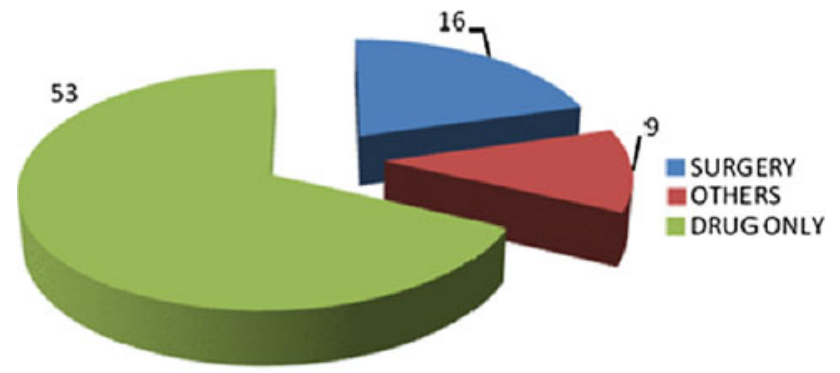

Fig. 3 Kind of treatment respondents were willing to accept

Table 3 Respondents' knowledge concerning the causes of breast developmental anomalies (BDA)

\begin{tabular}{lrr}
\hline Causes of BDA & $\begin{array}{l}\text { Frequency } \\
(n)\end{array}$ & $\%$ \\
\hline I don't know & 61 & 78 \\
Hereditary from birth, natural, genetic & 5 & 6 \\
A man sucking or playing with a woman's breast & 1 & 1 \\
Putting money in one's brassiere & 6 & 7 \\
Cancer & 1 & 1 \\
Other & 6 & 7 \\
Total & 78 & 100 \\
\hline
\end{tabular}

Table 4 Influence of breast developmental anomalies (BDA) on respondents in the family and school

\begin{tabular}{lcc}
\hline & Family & School \\
\hline No response & 0 & 6 \\
No problem & 55 & 61 \\
Embarrassment & 4 & 2 \\
Shyness & 3 & 5 \\
Teasing & 16 & 3 \\
Total & 78 & 78 \\
\hline
\end{tabular}

BDA, representing $5.7 \%$ of the 600 subjects examined. Our results concur with Simmons' [17] finding of breast asymmetry, caused primarily by macromastia.

The high prevalence of macromastia may result from heredity, increased hormonal secretion, or hormonal imbalance because the majority of the respondents were adolescents (Fig. 1). Our study differs from others that generally report polythelia as the most common form of BDA [7, 17]. Complete absence of one or both breasts and segmental failure in the development of a breast are so rare that they are unknown to most clinicians. Minor degrees of disparity in breast size usually are of developmental origin, whereas distinct hypertrophy is more reasonably ascribed to postnatal physiologic disturbances.

The most common malformation of the nipple is inversion. Less often, a developmental fissuring of the nipple is seen. The clinical importance of these anomalies is that they are historically established as developmental in origin and not confused with deformities of the nipple secondary to a pathologic process within the breast.

Whereas Kosters and Gotzsche [8] reported that it is the culture of most women in New York, USA to practice breast self-examination (BSE) periodically, this was not the case among the black young females in the central part of Ghana. The health care providers should therefore pay more attention to the young females and organize seminars on BSE in JHS to increase the BDA identification level among the young females.

As illustrated in Table 2, a high number of the respondents $(n=65,83 \%)$ had heard about BDA. Our results are similar to those of McMenamin et al. [11], who reported that most respondents in the Western population (81\%) had seen or heard something about BDA and breast cancer but that few took any action as a result. Also, previous reports from Nigeria, noting the lack of awareness, diagnostic facilities, treatment centers, and specialists, suggested that breast screening should be part of a routine medical checkup. Although our study showed an awareness level of $83 \%$, the results elaborated by McMenamin et al. [11] and Onwere et al. [13] are confirmed because $99 \%$ of the respondents in our study had never sought medical attention for their BDA despite their awareness of the condition. 
Effective practices should be encouraged during awareness seminars and programs.

Although surgical treatment for BDA has existed for many years, with advanced anesthetic procedures enabling surgeons to perform longer and more extensive operations safely, fear concerning that type of treatment for BDA still is high [15]. The results of the study show that few of the respondents opted for surgery as an acceptable treatment procedure (Fig. 3). Simmons' [17] study on BDA among black American and Caucasian girls suggested that surgical intervention for anomalies should be tailored and timed to the individual patient's situation and need not wait until adolescence is completed. The public should be made aware of the advantages and safety of aesthetic breast surgery through various informative media.

Table 3 shows that the majority of the respondents (78\%) had no knowledge of the causes of BDA, although most of them $(63 \%)$ had noticed the BDA within the first to third year of the anomaly (Table 1). Lettre et al. [10] reported that in terms of breast education, from adolescence every woman should be breast aware throughout her adult life. It is an important part of caring for her body. It means knowing how her breasts look and feel normally so that she notices any changes that might be unusual for her.

In 2003, the Ghana News Agency reported on a breast awareness seminar in the Ho Municipality of Ghana for female teachers. In that seminar, it was stated as not true that women who allowed men to suck or play with their breasts were at a higher risk of contracting breast diseases. In fact, the women were told that "it was rather a bonus since someone conversant with the feel of the breast could detect an anomaly more easily" [2]. Also, although thrusting money into the brassiere could not be said to cause a breast anomaly, it remains an unhealthy practice because the breast nipple has open pores likely to become infected.

Table 4 shows the problems that BDA caused for the respondents in their family and school respectively. The results show clearly that BDA had no influence on school activities or family life. This is also a contributing factor for the increasing BDA in Jamasi. No one cares about it even in the family, leading to the fact that these young females were not given any appropriate treatment.

\section{Conclusion}

The findings of the study suggest that BDA awareness was high among the young females in the central part of Ghana. However, only few of them were ready for surgical treatment, which in reality is the ultimate solution to their breast anomalies. Appropriate education and treatment should be encouraged for continual management of a high awareness level for BDA.
Acknowledgment We sincerely thank Mr. Thomas Diby, who was very instrumental in this study. He also helped to analyze the data.

\section{Conflict of interest None.}

Open Access This article is distributed under the terms of the Creative Commons Attribution Noncommercial License which permits any noncommercial use, distribution, and reproduction in any medium, provided the original author(s) and source are credited.

\section{References}

1. Agbenorku P, Akpalo J, Turkson E, Agbenorku M (2007) Breast diseases including breast developmental anomalies in Kumasi, Ghana. Niger J Plast Surg 3:11-14

2. Akoto G (2003) Ghana News Agency reported on a breast awareness seminar in the Ho Municipality of Ghana for female teachers. Daily J 12(6):23-24

3. Baker SB, Burkey BA, Thornton P, LaRossa D (2001) Juvenile gigantomastia: presentation of four cases and review of the literature. Ann Plast Surg 46:517-525

4. Bloom MD, Sara A, Maurice Y, Nahabedian D (2008) Gestational macromastia: a medical and surgical challenge. Breast $\mathrm{J}$ 11:492-495

5. Bostwick J (1990) Breast augmentation, reduction, and mastopexy. In: Jurkiewicz MJ, Krizek TJ, Mathes SJ, Ariyan S (eds) Plastic surgery principles and practice. Mosby, St. Louis, pp 458-467

6. Clement-Jones M, Schiller S, Rao E, Blaschke RJ, Zuniga A, Zeller R et al (2000) The short stature homeobox gene SHOX is involved in skeletal abnormalities in Turner syndrome. Hum Mol Genet 9:695-702

7. Haagensen CD (1967) Breasts. In: Rubin A (ed) Handbook of congenital malformation. WB Saunders Co, Philadelphia, pp 398-401

8. Kosters JP, Gotzsche PC (2003) Regular self-examination or clinical examination for early detection of breast cancer. Oxford University Press, New York, pp 45-56

9. Lee M (2000) Growth hormone deficiency as the only identifiable cause for primary amenorrhea. J Pediatr Adolesc Gynecol 13: 93-95

10. Lettre G, Jackson AU, Gieger C, Schumacher FR, Berndt SI, Sanna S, Eyheramendy S et al (2008) Identification of ten loci associated with height highlights new biological pathways in human growth. Nat Genet 40:584-591

11. McMenamin M, Barry H, Lennon AM (2005) A survey of breast cancer awareness and knowledge in a Western population: lots of light but little illumination. Eur J Cancer 41:393-397

12. Ohlsén L, Ericsson O, Beausang-Linder M(1996) Rapid, massive, and unphysiological breast enlargement. Eur J Plast Surg 9:100-102

13. Onwere S, Okoro B, Chigbu A (2008) Practice of antenatal clinical breast examination as a method of early detection of breast cancer by health care providers in a low resource setting. Arch Gynecol Obstet 278:115-117

14. Ravichandran D, Naz S (2006) A study of children and adolescents referred to a rapid diagnosis breast clinic. Eur J Pediatr Surg 16:303-306

15. Schurter M, Letterman G (1974) Breast deformities and their surgical repair. J Invest Dermatol 63:138-141

16. Sharma KS, Nigam A, Nita K, Uma C (2004) Unilateral gestational macromastia: a rare disorder. Malays J Pathol 26:125-128

17. Simmons PS (2008) Anomalies of the adolescent breast. Paediatr Child Health 18:85-87 